\title{
Empirical Approach To Predict Static Capacity Of Drilled Shafts Based On High Strain Dynamic Pile Test Results
}

\author{
Ahmed Elgamal \\ Mansoura Higher Institute of Engineering \& Technology \\ Mansoura, Egypt \\ Aelgamal@mc.edu.eg
}

\begin{abstract}
The axial compression capacity of drilled shafts using full-scale tests has received the attention of many geotechnical engineers. Regarding the extreme loads that large diameter shafts can resist, many cautions should be considered in the static load test (SLT) application. The High Strain Dynamic Pile Test (HSDPT) is recommended as it propounds a substantial saving of time, cost, and requirement of less space. Over the last decades, the signal matching analysis (e.g., Case Method, CAPWAP, and TNOWAVE) is considered to be the most common procedure followed to predict the axial static response of piles based on HSDPT results. This paper presents an empirical approach to predict the axial compression static capacity of drilled shafts based on HSDPT results. The ultimate static pile capacity has estimated from HSDT results using a simplified formula that conveys the ultimate capacity to the pile set occasioning from a hammer strike and not only the tip stratum properties but also other pile and soil/rock properties (shaft, tip soil, and rock). Numerous well-documented full-scale tests and finite element models were used to develop and validate the suggested formula.
\end{abstract}

Keywords: High Strain Dynamic test, large diameter shaft, static pile capacity, finite element modelling, PLAXIS 3-D.

\section{Introduction}

The traditional foundations are not appropriate to cope with revolutionary development in construction, which resulted in structural elements that carry massive loads. Drilled shafts are most efficiently utilized where a strong bearing layer is present. When placed to bear within or on a rock, extreme axial resistance can be achieved in a foundation with a small footprint [1]. This is why large diameter drilled shafts have been frequently used than other deep foundations types. Also, drilled shafts commonly utilized as an alternative solution in different subsurface conditions considering the mega-loads with minimal settlement [1].

Owing to the long-time needed to perform, high cost, limitation of test space, and transportation difficulties, contractors are seeking an alternative to conventional static load tests (SLTs) [2]. SLT is performed to verify the desired axial capacity of pile structures. The methods of statement and data analysis procedure for SLT are well documented in the literature "[3] [4]". Recently, High Strain Dynamic Pile Test (HSDPT) adopted to supplement and in some cases, replace SLT. With more advanced evaluation programs, the static bearing capacity determined from the results of HSDPT approximates the real static bearing capacity, determined from SLT [5].

Calibrating HSDPT results with SLT for one or more initial piles reduce the time and number of required tests [6]. Regarding the same pile, performing an HSDPT after the fully mobilized SLT (test load $=1.5$ times the pile static capacity) may mislead the wave results [7]. Dynamic measurements were accurately recorded for each hammer blow by the two strain transducers and two accelerometers that were fixed below the pile head, as shown in Fig. 1.

Consequently, the force $(\mathrm{F})$ and velocity $(\mathrm{V})$ records can be obtained as a function of time (t) by multiplying the pile cross-sectional area (A) and the modulus of elasticity (E) by the measured strain $(\varepsilon)$ and by integrating the recorded acceleration (a) with time, respectively, as shown in Fig. 2.

The main concept of driving formulas and its modifications "[8] [9] [10] [11]", is that the energy transferred to the pile top equals to work done by the pile resistance for the observed pile set $(\mathrm{S})$ in addition to the energy dissipated inside the pile and within the soil during the pile impact using Eq. 1.

$$
\mathrm{E}_{\mathrm{eff}}=\mathrm{e}_{\mathrm{eff}} \mathrm{W}_{\mathrm{h}} \mathrm{H}=\mathrm{Qult}_{\mathrm{ut}}\left(\mathrm{S}+\mathrm{S}_{\mathrm{c}}\right)
$$


Where $e_{\text {eff }}$ is the effective energy transferred to the pile top which can also be calculated using Eq. 2[6], eff is the hammer efficiency that can be utilized 0.55 and 0.097 as an average value for driven and bored piles, respectively, for dropped hammer, $Q_{u l t}$ is the ultimate pile static capacity and $S_{c}$ is an empirical coefficient according to the pile elastic compression during the impact load "[12] [13] [14] [15] [16]".

$$
E_{e f f}=\int_{0}^{t} F(t) V(t) d t
$$

The value of the pile set can be obtained by integrating the velocity with time [6], see Fig. 2. The pile capacity can be predicted from HSDPT after achieving a sufficient axial settlement that occurred during the impact event. A permanent net penetration of as little as $2 \mathrm{~mm}$ per impact may indicate that adequate movement has occurred during the impact event to mobilize the full capacity [6].

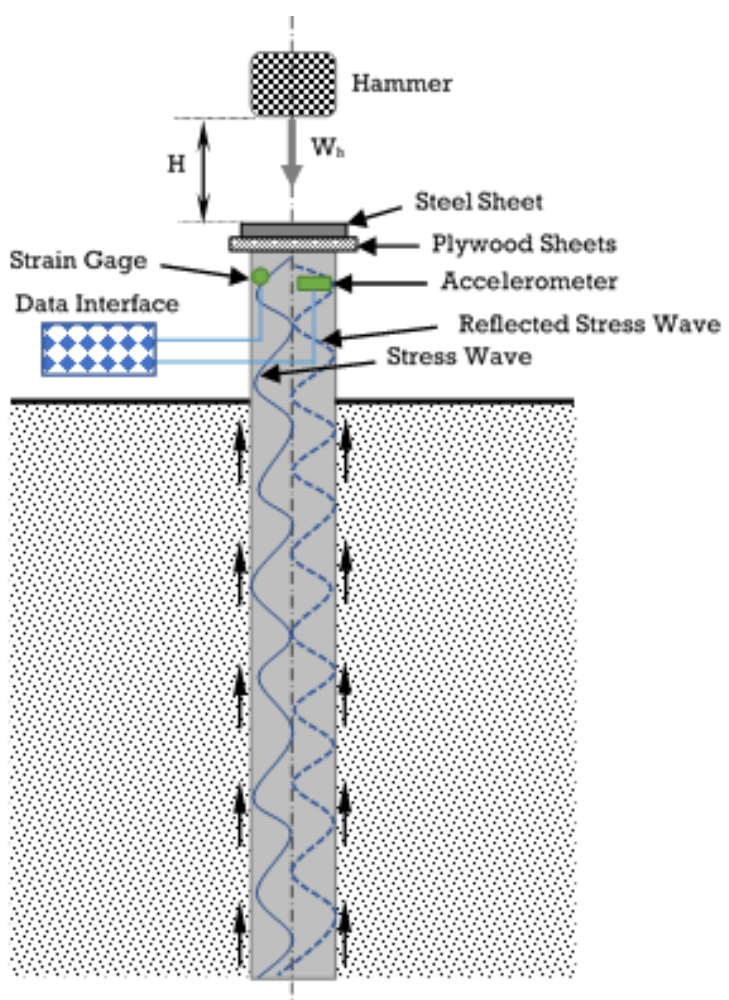

Fig. 1: Schematic sketch showing high strain dynamic testing of drilled shaft.

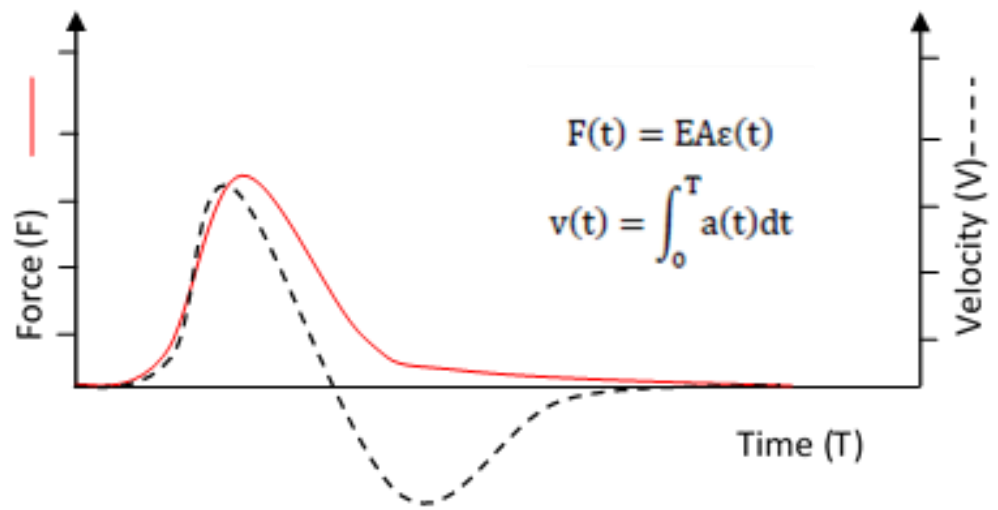

Fig. 2: Typical force and velocity schematic. 
Achieving a successful HSDPT for a drilled shaft requires appropriate hammer details (i.e., weight, height, and caution system) to cause sufficient pile movement. [6] recommends a hammer weight equal to $1 \%$ to $2 \%$ from the ultimate desired pile capacity. [17] suggests values of $\mathrm{W}_{\mathrm{h}}$ equal to $1 \%, 1.5 \%$, and $2 \%$ from the desired ultimate pile capacity for piles rested on a rock, friction piles, and drilled shafts with end bearing in coarse soils, respectively. The value of $\mathrm{H}$ should be varied from $0.3 \mathrm{~m}$ to $3 \mathrm{~m}$ according to the same research. For test construction purposes, the light hammer weight with significant height is more desirable than the heavy ones with low height [18].

Up to now, HSDPT is based on the practice, and the experience of one performed the test. The weight of the hammer with corresponding height still to be determined. Some researches make focus on the confusing details of HSDPT to ensure successful tests.[2] mentioned that dynamic tests will increasingly underestimate the results as the pile diameter and length increase, possibly because insufficient energy is transmitted. Also, the correlation was best for piles in sand and gravel compared with those in clay or in rock. [19] concluded that mobilized energy is a necessary requirement but an insufficient condition. If so, it would be beneficial to know the energy levels or the impact value, which can trigger dynamic pile settlement equal or similar to static pile settlement from SLT.

\section{The concept of the study}

This research aims to create an empirical relationship between the hammer weight and corresponding height based on the soil and pile properties considering the desired static capacity. Due to the few full-detailed historical data, Finite Element Models (FEMs) that simulate SLT and HSDPT had been developed to fit out a well-established SLT/HSDPT results database. Then formative a correlation between SLT and HSDPT to predict the axial compression capacity of large diameter shafts based on soil, pile, and drop weight properties.

The drilled shafts studied had a range of diameters (D) from $800 \mathrm{~mm}$ to $1500 \mathrm{~mm}$ (broadly pile diameters) embedded in different dense sandy soil layer $\left(\mathrm{D}_{\mathrm{r}}=30 \%, 60 \%\right.$, and $\left.80 \%\right)$ with depth $\left(\mathrm{L}_{\mathrm{s}}\right)$ and penetrated a limestone layer to a distance of 2D as shown in Fig. 3.

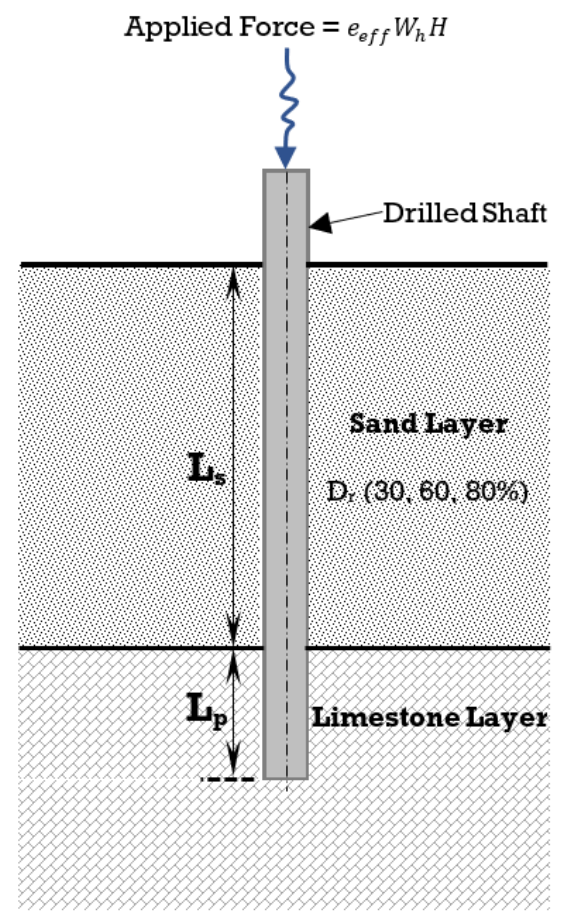

Fig. 3. The constitutive model used in the study.

The pile penetration distance $\left(\mathrm{L}_{\mathrm{p}}\right)$ in the limestone layer was analysed to be $2 \mathrm{D}, 3 \mathrm{D}$, and $4 \mathrm{D}$, but the results found out that the change of penetration depth has a slight effect on the pile behaviour under static and high strain dynamic tests. Table1 presents the pile's details modelled in FE analysis. 
Table 1: Piles' properties modeled in FE analysis.

\begin{tabular}{|c|c|c|c|c|c|c|}
\hline & & & \multicolumn{4}{|c|}{$\mathrm{D}(\mathrm{mm})$} \\
\hline & & & 800 & 1000 & 1200 & 1500 \\
\hline \multirow{4}{*}{$\underset{\Xi}{\Xi}$} & & 20D & 16 & 20 & 24 & 30 \\
\hline & $\mathrm{L}_{\mathrm{s}}(\mathrm{m})$ & 30D & 24 & 30 & 36 & 45 \\
\hline & & $40 \mathrm{D}$ & 32 & 40 & 48 & 60 \\
\hline & $\mathrm{L}_{\mathrm{sock}}(\mathrm{m})$ & $2 \mathrm{D}$ & 1.6 & 2.0 & 2.4 & 3.0 \\
\hline
\end{tabular}

In order to prepare the SLT-HSDPT results database, the FE procedure shall be verified to be used to model static and high strain dynamic pile tests as cleared in the following sections.

\section{Finite element modelling}

\subsection{Geometry and Boundary Conditions}

PLAXIS 3-D 2018 is used to perform three-dimensional finite element models to simulate SLTs and HSDPTs, respectively. Fig. 4 portrays the general layouts and soil meshing of the developed FEMs. For SLTs, the models extended to 50D and 30D in the horizontal and vertical directions, respectively, to release the effect of model boundary conditions. The right and left edges were constrained from the horizontal movement only to avoid instability in the model analysis.

For the HSDPTs, the viscous boundaries were $150 \mathrm{D}$ away from the pile center in each side in the horizontal plane (xy) and were applied to the bottom layer edge, which extended to 100D. This type of boundary was used to prevent errors from being caused by the reflection effect of dynamic waves [20]. The bottom boundary of each model was constrained in the horizontal and vertical directions.

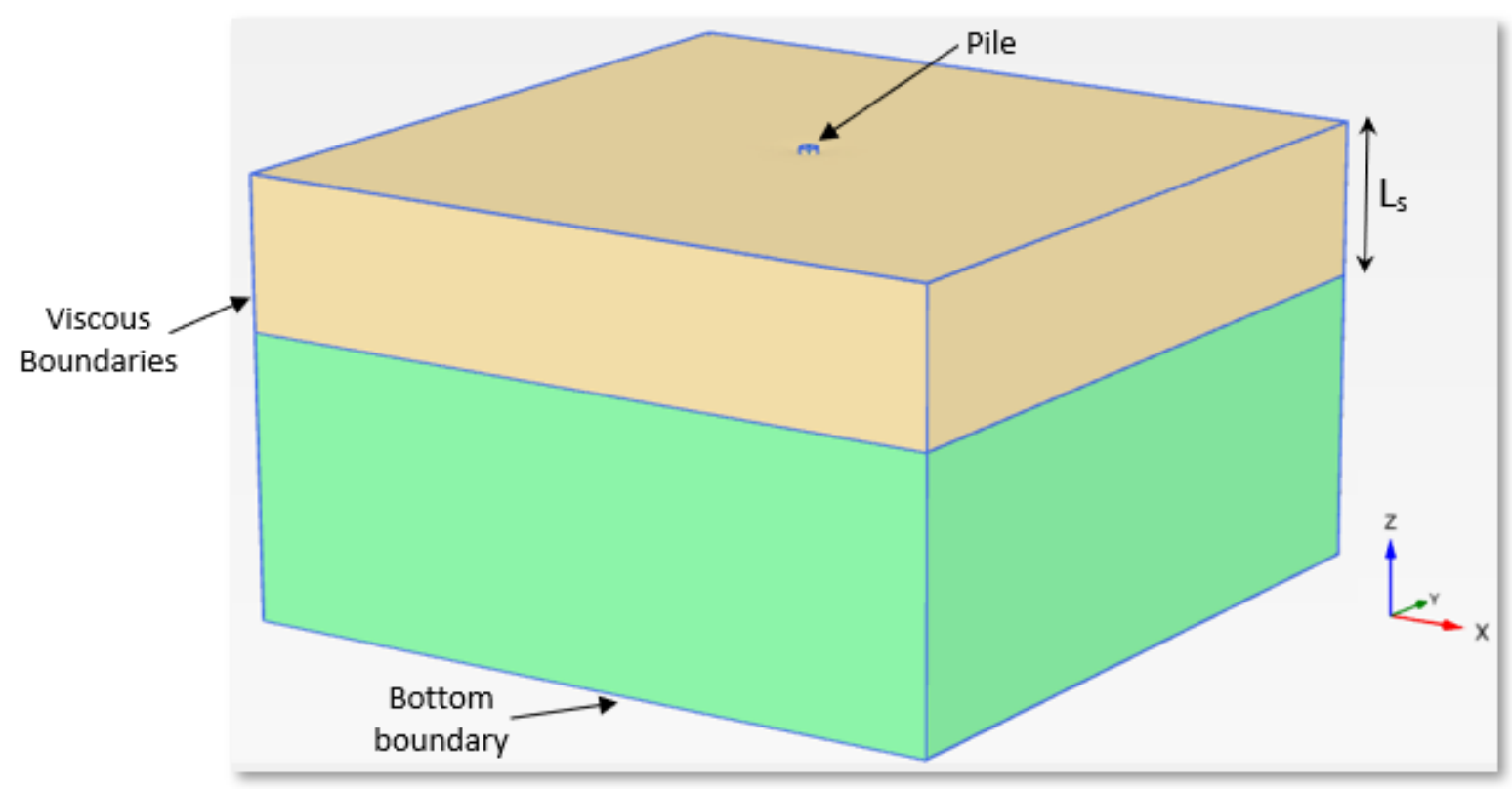

Fig. 4: FE model geometry and boundary conditions for HSDPTs (PLAXIS 3-D).

\section{2. Meshing}

3-D cubic volume shape was conducted around the pile, as shown in Fig. 5. The global mesh is medium to increase the accuracy and save time, 3-D cubic volume shape was conducted around the pile with local refinement mesh $\left(R_{\mathrm{f}}=0.1\right)$, as shown in Fig. 6. Many trials were conducted to ensure that the model reaches to the accurate values. 


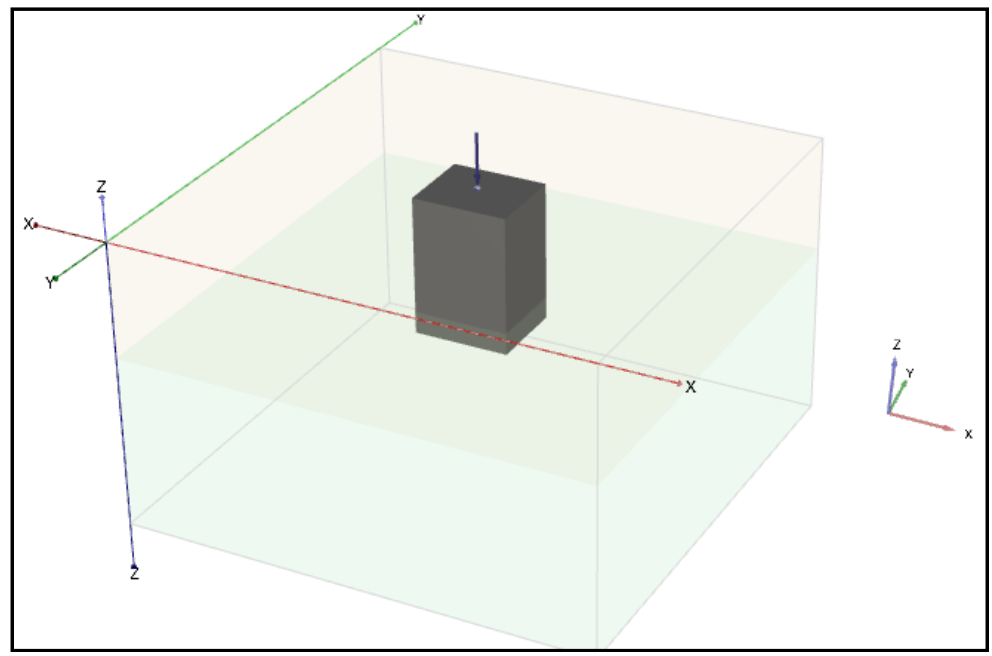

Fig. 5: 3-D cubic volume shape.

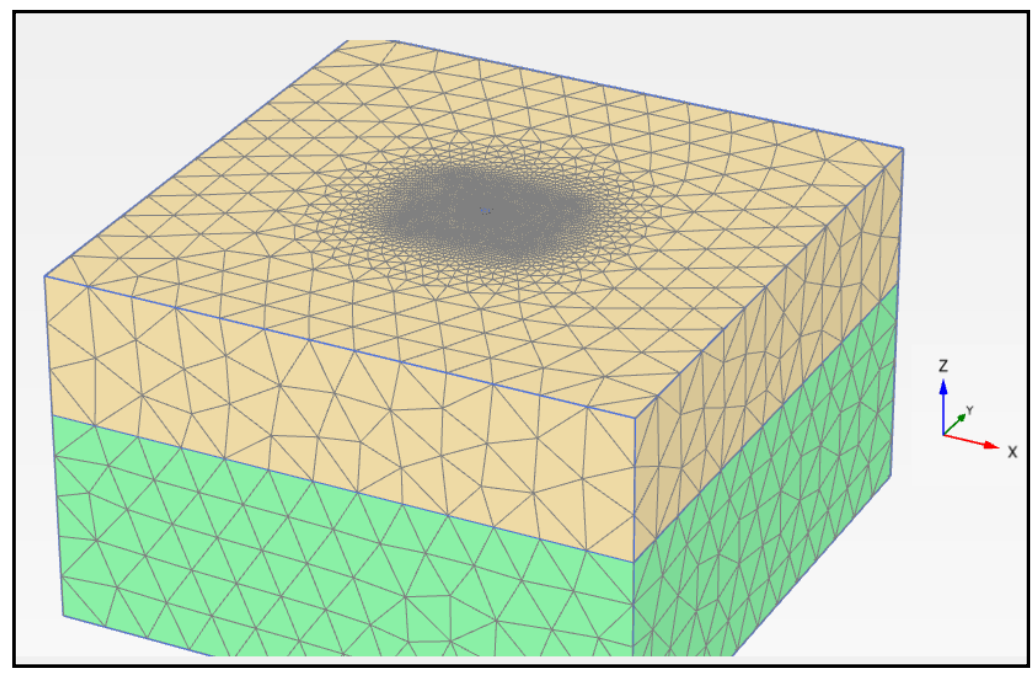

Fig. 6: Mesh generation (Global + local refinement).

\subsection{Soil and Pile Modelling}

The 3-D tetrahedron elements were used to represent the soil for SLTs and HSDPTs. Different meshing sizes were utilized to enhance the stress and settlement results. A zone of very fine mesh (with size $0.1 \mathrm{~m}$ ) was considered around and below the pile. Progressively, the mesh size is increased until they reach the boundaries locations.

The hardening soil (HSM) model is used to define the isotropic soil layers. This model is an advanced double hardening model (two surfaces represent the shear and compression yielding). The choice of this model is because of its ability to capture the fundamental properties of soil material. HSM requires three different stiffnesses; (i) the secant modulus ( $E_{50}^{\text {ref }}$ ) from the standard drained triaxial test that can be assigned as a function of soil modulus of elasticity using Eq. 3, (ii) the primary loading modulus (i.e., the tangent stiffness in oedometer loading) ( $E_{\text {oed }}^{\text {ref }}$ ) that equals to the value of $E_{50}^{\text {ref }}$, (iii) the unloading and reloading modulus $\left(\mathrm{E}_{\mathrm{ur}}^{\mathrm{ref}}\right)$ which equals three times the value of $\mathrm{E}_{50}^{\mathrm{ref}}$.

$$
\mathrm{E}_{50}^{\mathrm{ref}}=\mathrm{E} \frac{2-\mathrm{R}_{\mathrm{f}}}{2}
$$


Where, $R_{\mathrm{f}}$ is a failure modification factor equals to 0.9 (recommended $<1$, [21]. One of the advantages of HSM is that it considers the soil dilatancy angle $(\Psi)$ which usually can be estimated from the soil internal friction angle $(\varphi)(\Psi=$ $\varphi-30^{\circ}$ ) for soils that have a value of $\varphi$ greater than $30^{\circ}$. The pile was modelled as a linear-elastic material with mesh elements as the surrounding soil (mesh size was taken as $0.1 \mathrm{~m}$ ).

\section{4. Interface Elements}

The interaction between the soil/rock and the pile was defined using two elastic-perfectly plastic springs to simulate the gapping and slipping. It should be noted that in calculating the interface element parameters, the value of $\mathrm{R}$ represents the friction between soil and pile, which ranges from 0.6 to 1.0 according to pile material. The shear strength parameters at the pile interface were taken as $2 / 3$ that of the neighboring soil.

\subsection{Model Development}

The non-linear analysis of SLTs was divided mainly into four construction stages, as shown in "Fig. 7";

- Stage 1 considers the initial stresses before pile installation.

- Stage 2 Numerical instability is avoided by changing the soil in place of pile-to-pile material and pile weight. All displacement results were cleared before applying the static load.

- Stage 3 initiates by activating interface elements. In this stage, the static load was applied incrementally to simulate the pile loading process as in the field testing.

The analysis of HSDPTs is a linear time history analysis to consider the impact load and contains two analysis procedures. The first is an eigenvalue analysis type to determine the most effective time periods. The second analysis procedure is the two modes that have the highest modal participation ratio are selected to perform the linear-time history analysis ; this is the second analysis procedure.

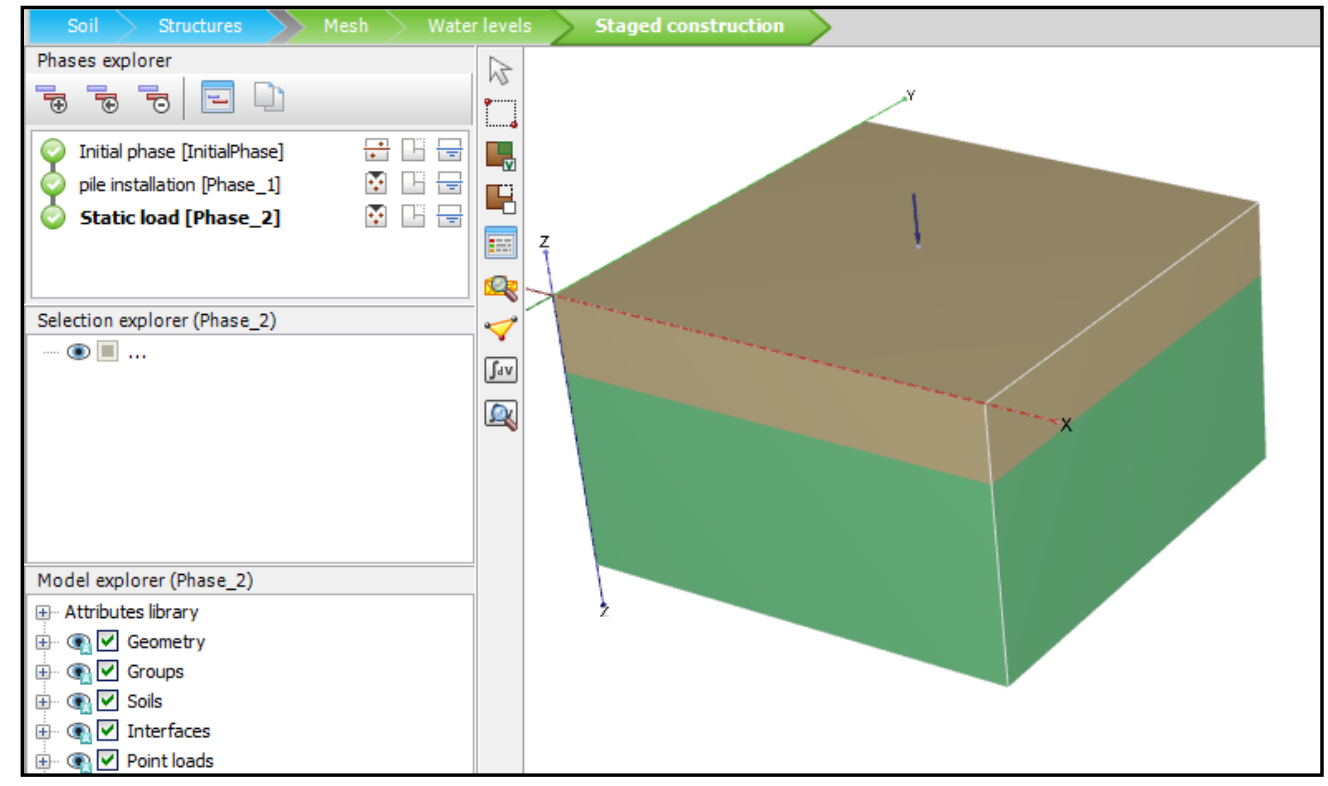

Fig. 7: Stages of construction (static load).

\subsection{HSDPT Simulation}

The impact load applied in the HSDPT could be simulated using a time history force function; see Fig. 2. The time history function measured in the full-scale test performed by [13] was selected to produce the effective energy transferred to the model piles head. Fig. 8 displays the time-history function used in the analysis of three different drops. It should be noted that the forces in Fig. 8 were multiplied by constant factors $(1,2,2.5,3,4,5$, and 6$)$ to generate adequate energies to drive the piles until they reach an acceptable displacement as previously illustrated. The HSDPT simulated model and its construction stages show in Fig. 9. 


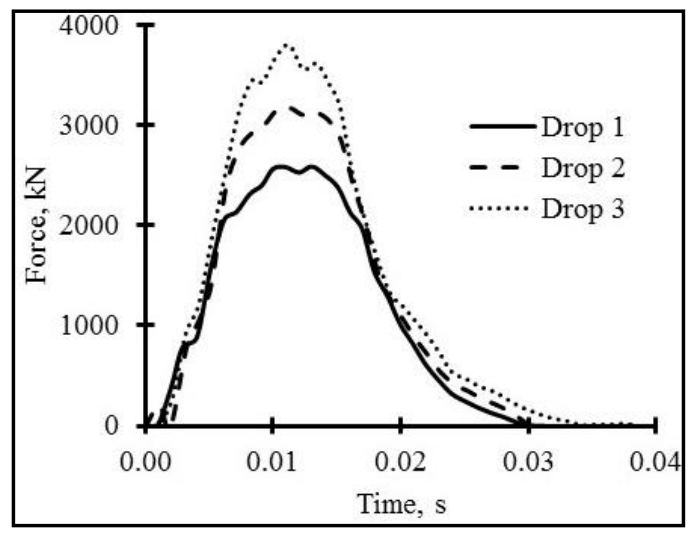

Fig. 8: Typically applied time history functions for HSDPTs.

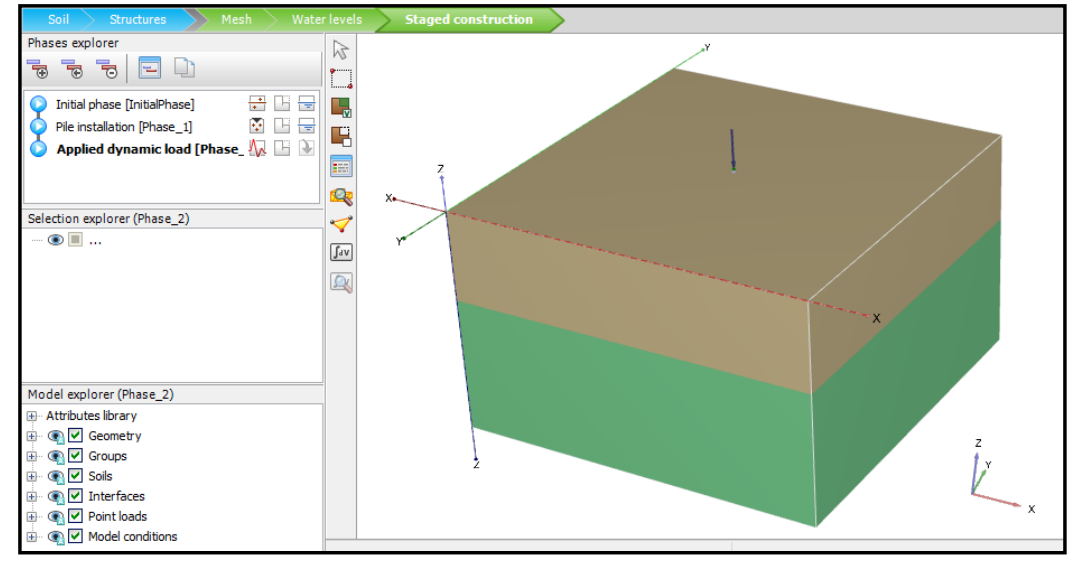

Fig. 9: Stages of construction (dynamic).

\subsection{FEM Verification}

[13](Hussein et al. 1992) performed full-scale static and high strain dynamic load tests on a 660mm diameter concrete pile with the equivalent pile properties presented in Table 2 . The pile was free headed cast-in-place penetrated sandy and clayey layers and rested on a weathered limestone with soil and rock properties shown in Table 3.

Table 2: Pile properties utilized for model calibration (after,[13]).

\begin{tabular}{|c|c|c|c|c|}
\hline $\mathbf{L}(\mathbf{m})$ & $\mathbf{D}(\mathbf{m m})$ & $\boldsymbol{\gamma}\left(\mathbf{k N} / \mathbf{m}^{\mathbf{3}}\right)$ & $\mathbf{v}$ & $\mathbf{E}(\mathbf{k P a})$ \\
\hline 13.70 & 660 & 25.67 & 0.2 & $2.4 \times 10^{7}$ \\
\hline
\end{tabular}

Table 3: soil/rock properties utilized for model calibration (after,[13]).

\begin{tabular}{|c|c|c|c|c|c|c|c|c|c|c|}
\hline Layer & $\begin{array}{c}\text { Depth } \\
(\mathbf{m})\end{array}$ & $\begin{array}{c}\text { Constitute } \\
\text { Model }\end{array}$ & $\begin{array}{c}\text { Drainage } \\
\mathbf{T y p e}\end{array}$ & $\begin{array}{c}\boldsymbol{\gamma} \\
\left(\mathbf{k N} / \mathbf{m}^{\mathbf{3}}\right)\end{array}$ & $\begin{array}{c}\mathbf{\Phi} \\
(\mathbf{d e g r e e})\end{array}$ & $\begin{array}{c}\mathbf{C} \\
(\mathbf{k P a})\end{array}$ & $\mathbf{v}$ & $\begin{array}{c}\mathbf{E}_{\text {oed }} \\
\left(\mathbf{k N} / \mathbf{m}^{2}\right)\end{array}$ & $\begin{array}{c}\mathbf{E}_{\mathbf{5 0}} \\
\left(\mathbf{k N} / \mathbf{m}^{2}\right)\end{array}$ & $\begin{array}{c}\mathbf{E}_{\mathbf{u r}} \\
\left(\mathbf{k N} / \mathbf{m}^{2}\right)\end{array}$ \\
\hline Sand & $\begin{array}{c}0.0- \\
9.15\end{array}$ & $\begin{array}{c}\text { Hardening } \\
\text { Soil model }\end{array}$ & Drained & 17 & 30 & 1 & 0.25 & 2500 & 2500 & 7500 \\
\hline Clay & $\begin{array}{c}9.15- \\
11.0\end{array}$ & $\begin{array}{c}\text { Hardening } \\
\text { Soil model }\end{array}$ & Undrained & 18 & 1 & 50 & 0.3 & 12000 & 12000 & 36000 \\
\hline Limestone & $\begin{array}{c}11.0- \\
40.0\end{array}$ & $\begin{array}{c}\text { Hardening } \\
\text { Soil model }\end{array}$ & Drained & 24 & 20 & 510.7 & 0.3 & 150000 & 150000 & 450000 \\
\hline
\end{tabular}

The interface parameters were calculated as illustrated in section 3.3 and presented in Table 4. Fig. 10 showed the measured and predicted pile-head load-displacement curves. A good agreement could be observed between the field results and that obtained from the finite element model. The limestone Uniaxial Compressive Strength (UCS) is $1458.6 \mathrm{kPa}$ [13]. 


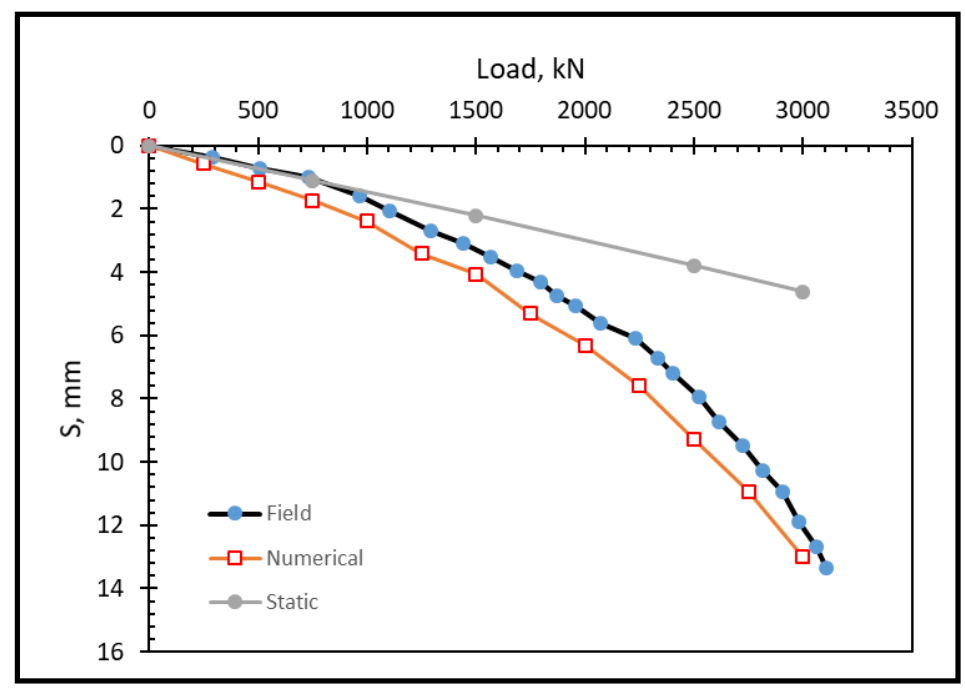

Fig. 10: Measured and predicted load-displacement relationship for SLT validation.

The three dropped weights presented as time function forces in Fig. 11 were applied to the 3-D soil-pile model to validate that the HSDPT can be modelled using PLAXIS 3-D 2018. No multiplier was applied to the three load functions (the same in the field test). As reported by [13], the hammer had a weight of $97.5 \mathrm{kN}$ and dropped from heights equal to $0.92 \mathrm{~m}, 2.14 \mathrm{~m}$, and $2.44 \mathrm{~m}$. Fig. 11 portrayed the measured and predicted time-velocity relationship. Good agreements are observed for the three different drops. The energies transferred to the pile top were calculated using Eq. 2 for the measured and the predicted waves. The measured transferred energies were found to be $8.2 \mathrm{kN}-\mathrm{m}, 14.95 \mathrm{kN}-\mathrm{m}$, and $25.5 \mathrm{kN}-\mathrm{m}$ for drops 1 , 2, and 3, respectively. The predicted ones were $10.8 \mathrm{kN}-\mathrm{m}, 17.85 \mathrm{kN}-\mathrm{m}$, and $25.6 \mathrm{kN}-\mathrm{m}$ for the three drops, respectively.

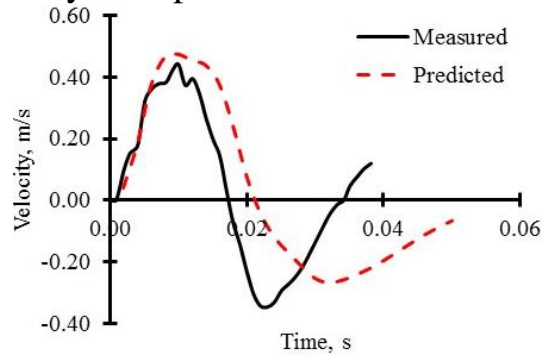

(a) Drop $1(0.92 \mathrm{~m})$

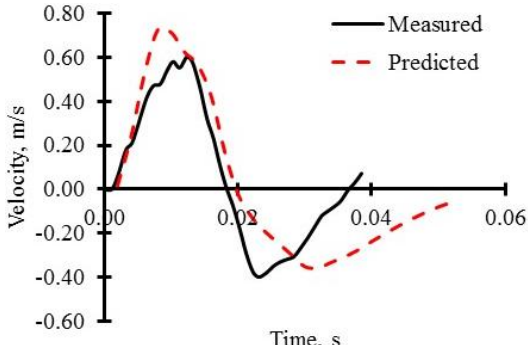

(b) Drop $2(2.14 \mathrm{~m})$

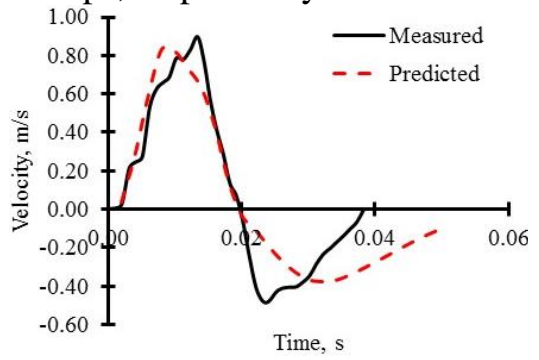

(c) Drop 3 (2.44 m)

Fig. 11: Measured and predicted velocity versus time for HSDPT validation.

Table 4: FEM material properties.

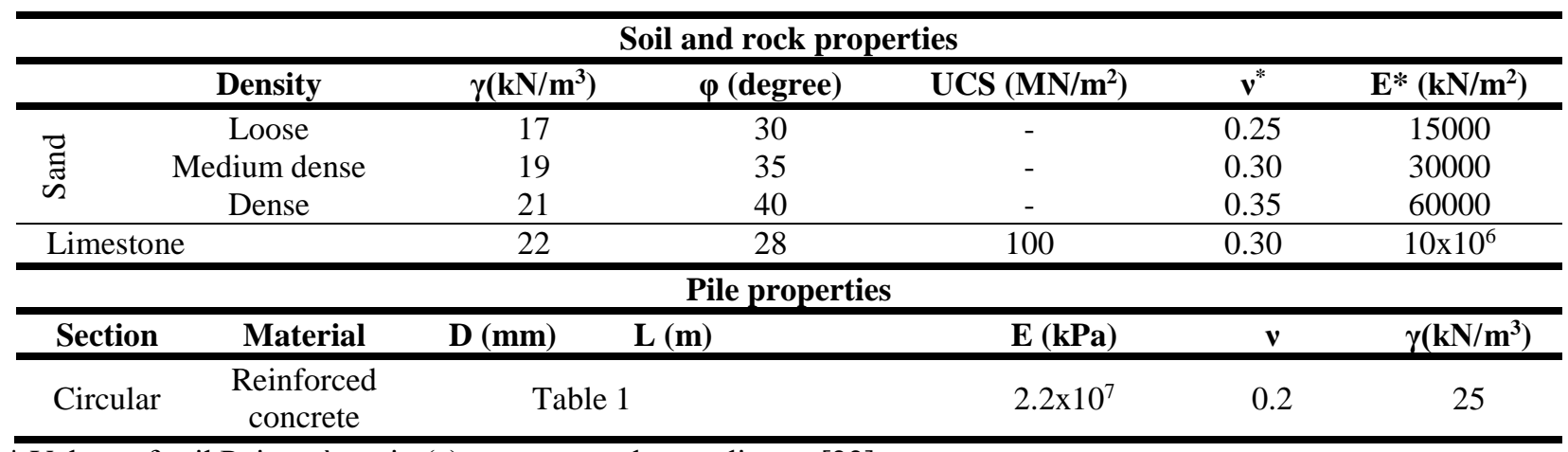

* Values of soil Poisson`s ratio (v) was assumed according to [22]. 


\section{Database establishment (SLT-HSDPT database)}

Table 5 presents the soil, rock, and pile properties utilized in the FE analysis. It should be noted that the soil and rock modulus of elasticity was estimated according to [22] and Eq. 3, respectively. The geometry, boundary condition, interface parameters, and analysis stages were the same as illustrated in sections 3.1 to 3.4. The three load functions presented in section 3.5 were utilized by applying multiplier factors to achieve an adequate displacement (i.e., $>2 \mathrm{~mm}$ ).

The finite element analysis results are presented in Table 5 for each pile diameter from $800 \mathrm{~mm}$ to $1500 \mathrm{~mm}$. All analysis models were performed based on test data presented by [13], so the value of $e_{\text {eff }}$ can be used equal to 0.097.

As previously discussed, the eigenvalue analysis type was performed on each FE model to obtain the most critical modes of shape. Choose the maximum of two-controlling time periods (modes of shape); the HSDPT results can be estimated from the FE time-history analysis. The SLTs were simulated using PLAXIS 3-D 2018.[3] is the method was applied to the SLT model results to predict the static capacity $\left(\mathrm{Q}_{10 \%}\right)$.

Table 5: Inputs and outputs of FEMs.

\begin{tabular}{|c|c|c|c|c|c|c|c|c|c|c|}
\hline \multirow{9}{*}{$\begin{array}{l}\sigma \\
\text { II } \\
\stackrel{\infty}{0} \\
\Xi \\
\equiv\end{array}$} & $\mathrm{L}_{\mathrm{p}}(\mathrm{m})$ & \multicolumn{3}{|c|}{17.6} & \multicolumn{3}{|c|}{25.6} & \multicolumn{3}{|c|}{33.6} \\
\hline & $\mathrm{L}_{\mathrm{s}}(\mathrm{m})$ & \multicolumn{3}{|c|}{16} & \multicolumn{3}{|c|}{24} & \multicolumn{3}{|c|}{32} \\
\hline & L $\mathrm{L}_{\text {sock }}(\mathrm{m})$ & \multicolumn{3}{|c|}{1.6} & \multicolumn{3}{|c|}{1.6} & \multicolumn{3}{|c|}{1.6} \\
\hline & $\mathrm{D}_{\mathrm{r}}(\%)$ & 30 & 60 & 80 & 30 & 60 & 80 & 30 & 60 & 80 \\
\hline & $\mathrm{UCS}\left(\mathrm{MN} / \mathrm{m}^{2}\right)$ & 1.4 & 1.4 & 1.4 & 1.4 & 1.4 & 1.4 & 1.4 & 1.4 & 1.4 \\
\hline & $\mathrm{H}(\mathrm{m})$ & 4.8 & 2.8 & 2.2 & 4.3 & 1.6 & 1.2 & 3.2 & 1.5 & 1.0 \\
\hline & $\mathrm{W}_{\mathrm{h}}(\mathrm{kN})$ & 154 & 170 & 186 & 334 & 370 & 406 & 436 & 458 & 506 \\
\hline & $\mathrm{S}(\mathrm{mm})$ & 3.51 & 3.46 & 3.42 & 4.89 & 4.75 & 4.63 & 6.41 & 5.9 & 5.45 \\
\hline & $\mathrm{Q}_{\text {ult }}(\mathrm{kN}) \times 10^{4}$ & 0.84 & 1.58 & 2.15 & 1.40 & 4.2 & 5.98 & 3 & 6.90 & 10.98 \\
\hline \multirow{9}{*}{ 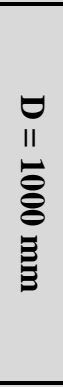 } & $\mathrm{L}_{\mathrm{p}}(\mathrm{m})$ & \multicolumn{3}{|c|}{22} & \multicolumn{3}{|c|}{32} & \multicolumn{3}{|c|}{42} \\
\hline & $\mathrm{L}_{\mathrm{s}}(\mathrm{m})$ & \multirow{2}{*}{\multicolumn{3}{|c|}{$\frac{20}{2}$}} & \multicolumn{3}{|c|}{30} & \multicolumn{3}{|c|}{40} \\
\hline & $\mathrm{L}_{\text {sock }}(\mathrm{m})$ & & & 2 & \multicolumn{3}{|c|}{2} & \multicolumn{3}{|c|}{2} \\
\hline & $\mathrm{D}_{\mathrm{r}}(\%)$ & 30 & 60 & 80 & 30 & 60 & 80 & 30 & 60 & 80 \\
\hline & $\mathrm{UCS}\left(\mathrm{MN} / \mathrm{m}^{2}\right)$ & 1.4 & 1.4 & 1.4 & 1.4 & 1.4 & 1.4 & 1.4 & 1.4 & 1.4 \\
\hline & $\mathrm{H}(\mathrm{m})$ & 3 & 2.7 & 1.85 & 1.75 & 1.25 & 0.9 & 0.77 & 0.55 & 0.72 \\
\hline & $\mathrm{W}_{\mathrm{h}}(\mathrm{kN})$ & 248 & 283 & 320 & 653 & 723 & 794 & 853 & 947 & 1041 \\
\hline & $\mathrm{S}(\mathrm{mm})$ & 2.7 & 2.65 & 2.59 & 6.0 & 5.76 & 5.53 & 8.07 & 7.4 & 6.3 \\
\hline & $\mathrm{Q}_{\text {ult }}(\mathrm{kN}) \times 10^{4}$ & 2.12 & 2.54 & 4.03 & 6.80 & 10.23 & 15.13 & 19.23 & 28.62 & 21.66 \\
\hline \multirow{9}{*}{ 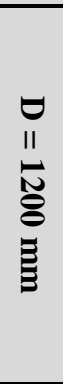 } & $\overline{L_{p}(m)}$ & \multicolumn{3}{|c|}{26} & \multicolumn{3}{|c|}{38} & \multicolumn{3}{|c|}{50} \\
\hline & $\mathrm{L}_{\mathrm{s}}(\mathrm{m})$ & \multirow{2}{*}{\multicolumn{3}{|c|}{$\frac{24}{2}$}} & \multirow{2}{*}{\multicolumn{3}{|c|}{$\frac{36}{2}$}} & & 48 & \\
\hline & $\mathrm{L}_{\text {sock }}(\mathrm{m})$ & & & & & & & & 2 & \\
\hline & $\mathrm{D}_{\mathrm{r}}(\%)$ & 30 & 60 & 80 & 30 & 60 & 80 & 30 & 60 & 80 \\
\hline & $\mathrm{UCS}\left(\mathrm{MN} / \mathrm{m}^{2}\right)$ & 1.4 & 1.4 & 1.4 & 1.4 & 1.4 & 1.4 & 1.4 & 1.4 & 1.4 \\
\hline & $\mathrm{H}(\mathrm{m})$ & 2.6 & 2.3 & 1.6 & 1.7 & 1.3 & 1.1 & 1 & 0.8 & 0.6 \\
\hline & $\mathrm{W}_{\mathrm{h}}(\mathrm{kN})$ & 1125 & 1253 & 1480 & 1820 & 1950 & 2250 & 2430 & 2800 & 3150 \\
\hline & $\mathrm{S}(\mathrm{mm})$ & 2.27 & 2.21 & 2.15 & 3.36 & 3.15 & 3.0 & 4.42 & 4.0 & 3.72 \\
\hline & $\mathrm{Q}_{\text {ult }}(\mathrm{kN}) \times 10^{4}$ & 5.79 & 7.0 & 11.1 & 11.9 & 16.3 & 20.7 & 24.76 & 33.07 & 47.0 \\
\hline & $\mathrm{L}_{\mathrm{p}}(\mathrm{m})$ & & 33 & & & 48 & & & 63 & \\
\hline & $\mathrm{L}_{\mathrm{s}}(\mathrm{m})$ & & 30 & & & 45 & & & 60 & \\
\hline$\theta$ & $\mathrm{L}_{\text {sock }}(\mathrm{m})$ & & 3 & & & 3 & & & 3 & \\
\hline & $\mathrm{D}_{\mathrm{r}}(\%)$ & 30 & 60 & 80 & 30 & 60 & 80 & 30 & 60 & 80 \\
\hline पू & $\mathrm{UCS}\left(\mathrm{MN} / \mathrm{m}^{2}\right)$ & 1.4 & 1.4 & 1.4 & 1.4 & 1.4 & 1.4 & 1.4 & 1.4 & 1.4 \\
\hline$\stackrel{0}{E}$ & $\mathrm{H}(\mathrm{m})$ & 2.1 & 2.0 & 1.45 & 1.9 & 1.4 & 1.0 & 1.4 & 1.0 & 0.73 \\
\hline $\mathrm{E}$ & $\mathrm{W}_{\mathrm{h}}(\mathrm{kN})$ & 1256 & 1433 & 1619 & 1918 & 2222 & 2545 & 2645 & 3101 & 3591 \\
\hline & $\mathrm{S}(\mathrm{mm})$ & 0.97 & 0.966 & 0.96 & 2.79 & 2.60 & 2.42 & 3.52 & 3.23 & 2.98 \\
\hline & $\mathrm{Q}_{\text {ult }}(\mathrm{kN}) \times 10^{4}$ & 8.08 & 9.13 & 13.70 & 13.61 & 20.04 & 30.21 & 22.3 & 34.04 & 50.27 \\
\hline
\end{tabular}




\section{Results discussion}

The results of SLT and HSDPT models have been analysed, and it was found that there is an empirical relationship eq. 4 between static capacity $(\mathrm{kN})$ of drilled shaft piles that penetrate soil/rock profiles as shown in Fig. 3 with the following variables:

1. $\mathrm{W}_{\mathrm{h}}$, the weight of the hammer, $\mathrm{kN}$;

2. $\mathrm{H}$, corresponding drop height, $\mathrm{m}$;

3. $e_{\text {eff }}$, the efficiency of drop;

4. $\mathrm{D}_{\mathrm{r}}$, the relative density of the sandy layer;

5. D, pile diameter, $\mathrm{mm}$;

6. $\mathrm{L}_{\text {sock }}$, socket length, $\mathrm{m}$;

7. $\mathrm{L}_{\mathrm{P}}$, pile penetration distance in the limestone layer, $\mathrm{m}$;

8. S, pile settlement, $\mathrm{mm}$;

9. UCS, uniaxial compression strength of rock, $\mathrm{MN} / \mathrm{m}^{2}$;

10. $\mathrm{L}_{\mathrm{s}}$, depth of sandy layer, $\mathrm{m}$; The pile penetration distance $\left(\mathrm{L}_{\mathrm{p}}\right)$ in the limestone layer

11. $\sigma_{\mathrm{v} 0}$, effective stresses through pile shaft, $\mathrm{MN} / \mathrm{m}^{2}$,

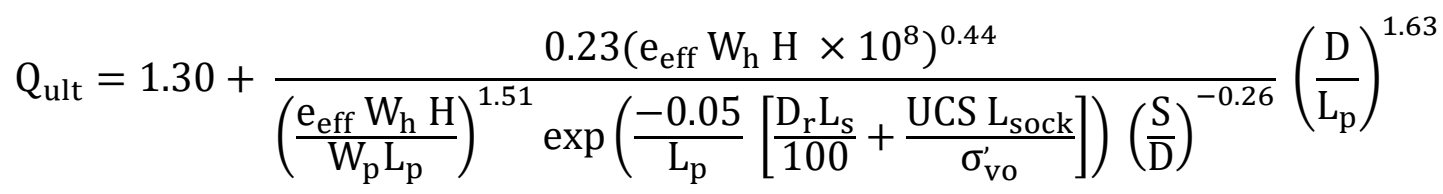

It seems there is a relationship between measured and predicated static pile capacity for different pile diameters, as shown in Fig. (12). By using this relation no need to calibrate HSDPT with full-scale SLT. It can make safe more money, time, and effort.

An increasing relationship between pile weight and the weight of the hammer is shown in Fig. (14). This relationship is expected, especially in drilled shat, as the weight of the hammer produces a force that causes a pile movement, and this force supposed to be close to the weight of the pile.

There is a clear relationship between static pile capacity and hammer height multiply by corresponding drop height for different pile diameters, as shown in Fig. (13). This relation could be easily used to estimate the suitable hammer weight and corresponding drop height for a successful drop from one time. It will save time and money.

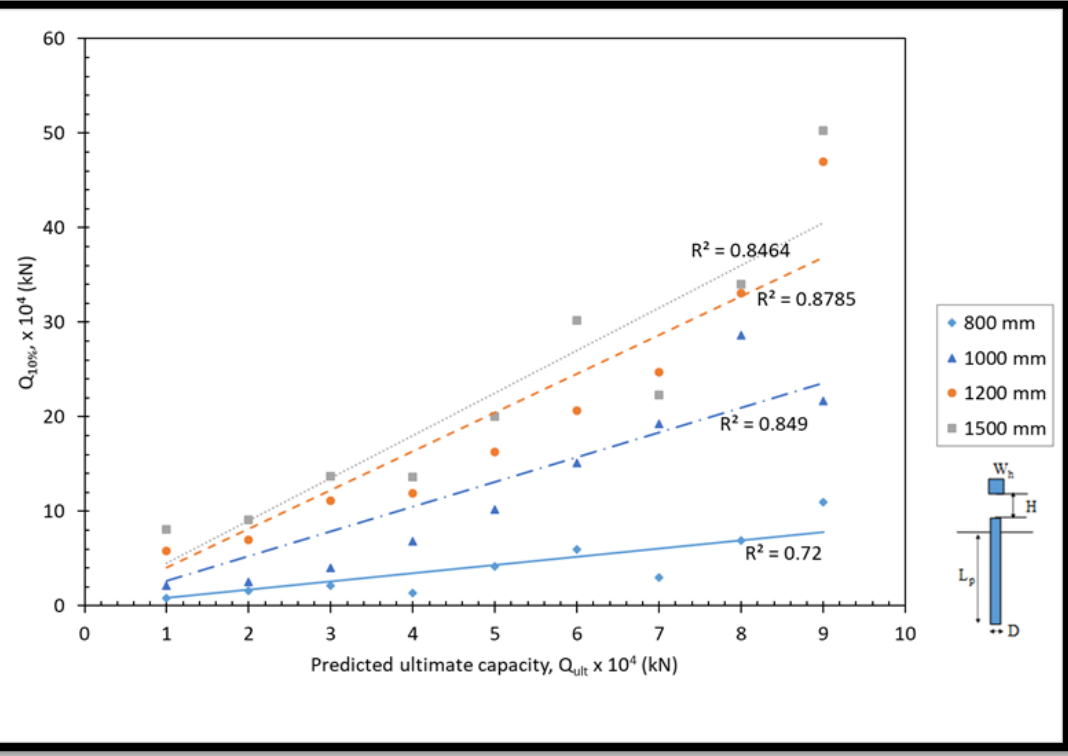

Fig. 12: Correlation between measured and predicted static pile capacity. 


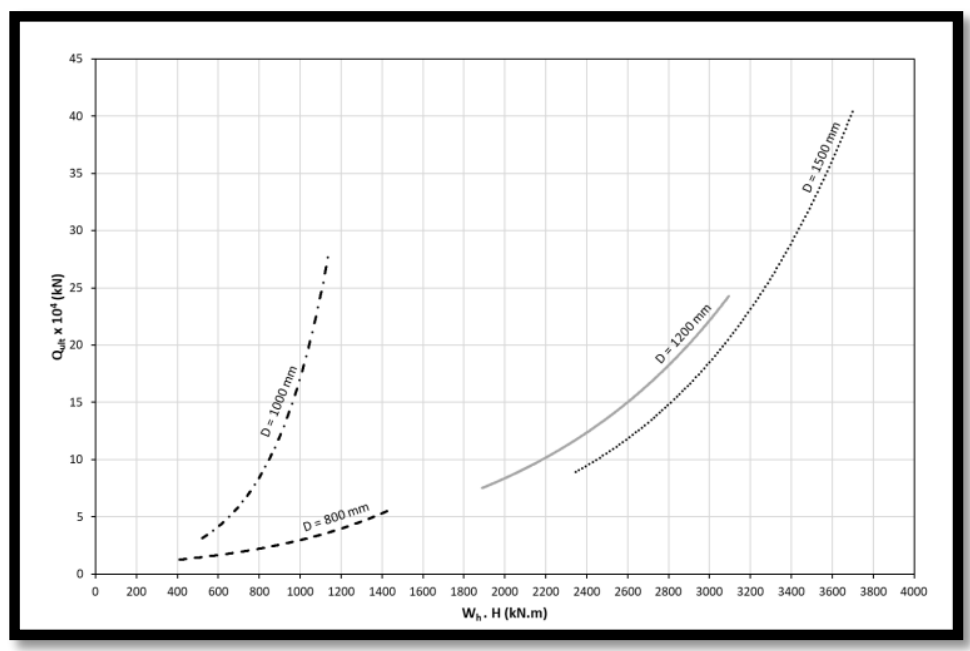

Fig. 13: Correlation between (hammer height multiple by corresponding height) and ultimate static pile capacity.

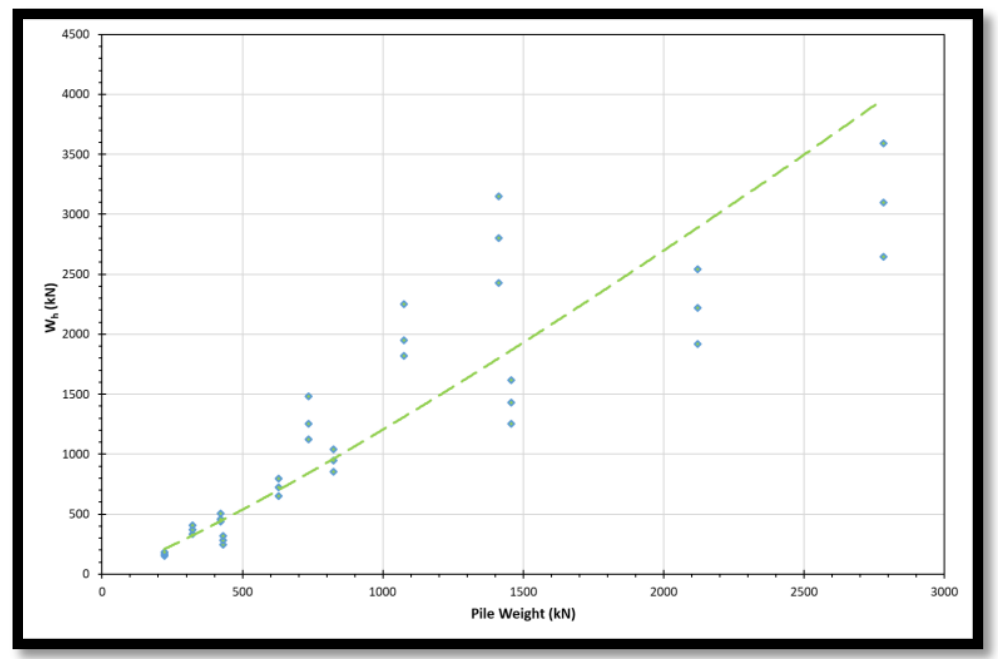

Fig. 14: Correlation between pile weight and hammer weight.

\section{Conclusion}

A large diameter drilled shaft is broadly used as a reliable deep foundation that could carry mega loads with a minimal settlement, and implementation constraints. The determination of static pile capacity is essential for the design process. The more the pile capacity determined is accurate the more money, effort and time is saved. SLT is a traditional test that is used to prove the ultimate static capacity of a pile, but this test costs money. So, HSDPT becomes commonly used for evaluation of the static pile capacity as it avoids the defects of SLT.

The success of the HSDPT strongly depends on the hammer energy and soil nature. HSDPT proves that it is a tangible, proven tool of static pile capacity if the pile has sufficient movement to produce skin friction and end bearing. The pile movement is based on the hammer weight and corresponding height that must be suitable for soil/rock conditions.

Although the HSDPT is broadly used in the last fifteen years, there is a shortage of well-documented full-details data of the HSDPTs, which calibrated with SLTs and real soil/rock conditions. Few reliable results are available, and it used to establish a core of the database. The FE models were devolved to recover the lack of data and to complete the database. The FE analysis is used to simulate both SLTs and HSDPTs, and the FE models' results are close to full-scale results.

HSDPT provides a practical and powerful tool for verification of the static pile capacity, which necessary for geotechnical pile design. There is a need for an international free use database of HSDPT results that is calibrated with SLTs, 
to change the test from being experience-based into casual user based. This research will contribute to this attitude. More studies are needed to cover all soil/rock conditions with reliable data.

\section{References}

[1] O'Neill, M. W., and Reese, L. C. (1999). "Drilled shaft: construction procedures and design methods." FHWA Report No. IF-99-025.

[2] Long, M. (2007). “ Comparing dynamic and static test results of bored piles." Proceeding of the Institution of Civil Engineering, Geotechnical Engineering 160, January 2007, Issue GEI, Pages 43-94.

[3] Davisson, M. T. (1972). "High capacity piles." Proc., Lect. Series on Innovation in Found. Const., ASCE, Illinois Section, Chicago, p. 52.

[4] Fellenius, B. H. (1980). “The analysis of results from routine pile load tests. Ground Engineering.", London, Vol. 13, No. 6, pp. $19-31$.

[5] Schell, P., Szilvagyi, L., and Wolf, A. (2015). "Case study of a static-dynamic pile load test program in Hungary.", Proceedings of the XVI ECSMGE, Geotechnical Engineering for Infrastructure and development, DOI:101680/ecsmge.60678.

[6] ASTM (2017). "Standard test method for high-strain dynamic test," Designation: D4945 - 17.

[7] Briaud, J.-L., Ballouz, M., and Nasr, G. (2000). "Static capacity prediction by dynamic methods for three bored piles.", ASCE, Journal of Geotechnical and Geoenvironmental Engineering, Vol. 126, No. 7, July 2000, Paper No. 17460.

[8] Gates, M. (1957). "Empirical formula for predicting pile bearing capacity." ASCE March 1957, vol. 27,pp. 65-66.

[9] ENR (1965). "Michigan pile test program test results are released," Michigan State Highway Commission, March 1965, Eng. News-Record, pp. 26-28, 33-34.

[10] Olson, R., and Flaate, K. (1967). "Pile-driving formulas for friction piles in sand.", Journal of Soil Mechanics \& Foundations Division, vol. 92, pp. 279-296.

[11] Salgado, R., Zhang, Y. Abou-Jaoude, G., Loukidis, D., and Bisht, V. (2017). "Pile driving formulas based on pile wave equation analyses.", Computers and Geotechnics, Volume 81, January 2017, Pages 307-32.

[12] PC, L., and Broms, B. (1990). "Influence of pile driving hammer performance on driving criteria." Geotech Engineering , vol. 21,1990, pp. 63-69.

[13] Hussein, M., Townsend, F., Rausche, F., and LIKINS, G. (1992). "Dynamic testing of drilled shafts." Transportation Research Record, 1336.

[14] Allen, T. (2005). "Development of the WSDOT Pile Driving Formula and its calibration for Load and Resistance Factor Design (LRFD)," WA-RD 610.1., Final research report, March 2005,Washington State Department of Transportation.

[15] Lam, J. (2007). "Termination criteria for high-capacity jacked and driven steel H-piles in Hong Kong," Ph.D. thesis, The University of Hong Kong, Hong Kong, China.

[16] Mostafa, Y. (2011). "Onshore and offshore pile installation in dense soils.” Journal of American Science, 2011;7(7),pp. 549-563.

[17] Robinson, B., Rausche, F., Likins, G., and Ealy, C. (2002). "Dynamic Load Testing of Drilled Shafts at National Geotechnical Experimentation Sites." Deep Foundations 2002: An International Perspective on Theory Design, Construction, and Performance.

[18] Hussein, M., Likins, G., and Rausche, F. (1996). "Selection of a hammer for high-strain dynamic testing of cast-in-place shafts." Fifth International Conference on the Application of Stress-Wave Theory to Piles, Orlando, Florida, USA.

[19] Svinkin, MR (2019). "Sensible determination of pile capacity by dynamic methods.", Geotechnical research 6(1):5267, https://doi.org/10.1680/jgere.18.00032.

[20] Lysmer, J., and Waas, G. (1972). "Shear waves in plane infinite structures.", ASCE, Journal of Engineering Mechanics, Feb. 1972, vol. 98, pp. $85-105$.

[21] PLAXIS 3-D (2018). “PLAXIS 3-D Manual”.

[22] Bowles, J.E. (1996) "Foundation analysis and design.”, 5th Edition, The McGraw-Hill Companies, Inc., New York. 